\title{
Customer relationship management technology
}

\author{
A commodity or distinguishing factor?
}

\author{
Wolfgang Messner \\ Softlab GmbH, Germany
}

'Data mining has long been hyped as a means to discover hidden relationships in large data sets. However, the underlying algorithms are mathematically complex and only experts understand if and how well the algorithm matches the properties of the business problem.'

Wolfgang Messner is a Senior Management Consultant with Softlab GmbH in Frankfurt. His focus is on the design of strategic instruments in the area of customer relationship management (CRM), the optimization of business processes, and planning and implementation of the underlying IS/ITinfrastructure. He has had similar positions in the area of CRM with other leading consulting companies. He has a doctorate degree in Economics (Dr. rer. pol.) from the University of Kassel (Germany), an MBA from the University of Wales (UK) and an advanced degree in Computing Science (Dipl.Inform.) from the Technical University Munich (Germany). He is author of several articles with magazines and books and a frequent speaker on international conferences. He can be contacted at wolfgang.messner@softlab.de or wolfgang.messner@gmail.com.

\begin{abstract}
CRM has changed the way companies handle customer enquiries, advertise and sell their products or manage the entire relationship with their customers. As the power of CRM technology has expanded, companies have come to view it as a resource ever more critical to their success in customer management. CRM technology has delivered great benefits to some firms, even propelling a few into positions of industry leadership, but for most businesses it is a continuous source of frustration, disappointment and costs. It has led managers to plough cash into misguided CRM initiatives, sometimes with catastrophic ROI figures. In addition to playing a direct role in cost, CRM technology often alters the cost drivers of activities in ways that can improve a company's value proposition. This paper looks at the evolution of CRM and CRM technology, analyses its current status and provides recommendations on how and when to best utilize CRM technology.
\end{abstract}

Keywords: adoption cycle, CRM, customer relationship management, hype cycle, overshooting, information technology management

\section{The evolution of CRM}

Customer Relationship Management (CRM) is a strategic and action-oriented view on the relationship between the customer and a company [22, p. 30]. CRM provides methodologies, strategies, processes and technologies to support a redesign of this relationship. 
Two entirely different trends from two science disciplines had the largest influence on CRM: on the one hand in the area of marketing the advance from transaction marketing to relationship marketing and on the other hand within computing science the development from information management to customer knowledge management.

\section{From transaction marketing to relationship marketing}

The historical interpretation of the term 'marketing' considers a purchase to be a unique transaction [15, p. 6]. This also implies that preceding transactions do not have substantial influence on forthcoming transactions. Hence acquisition of new customers is at the heart of the company's business strategy with customer retention being less important.

But at the end of the $20^{\text {th }}$ century, capital and work have lost their importance as the driving force for generating value. The enterprise of the $21^{\text {st }}$ century is an integrator that tries to offer as much information, and as many products and services, as possible. Based on deep knowledge about the customer, it shapes its offerings and combines them one-stop at the company's portal.

The need for superior customer knowledge was the driving force for the move from transaction-based marketing to relationship marketing. Avoiding customer attrition and promoting retention has become a key element in the new business model of the information age. But just as with transaction marketing, the focus still remains on the customer segment. Only the next evolutions are putting the individual customer into the limelight.

With One-to-One marketing the company is approaching every customer at the perfect time with a customized offering '. . . bringing within reach the Holy Grail of differentiation' [29, p. 94]. In addition to Oneto-One marketing, customized marketing is providing a further individualization of products, which are customized and bundled to match the needs of the individual customer. This further helps in achieving '... distinctiveness [which] is what in the end determines a company's profitability and assures its survival' [3, p. 7]. This approach is applied to complete markets with the help of information technology.

\section{From information management to customer knowledge management}

In the past, the introduction of new information management systems has been driven by a dominance of technology. The power of new systems was initially heralded by the IT department, and little or no interaction happened with the actual end-user. Later, the nature of IT as an instrument for streamlining processes and achieving cost reduction was recognized. Especially for processing mass data, new systems were introduced handling functional areas like accounting, sales or the control of production facilities [18, p. 24-5].

Application integration has then taken one of two basic forms:

- Manual batch loads between stand-alone core business systems and sometimes towards information or customer management systems.

- Selected point-to-point integration.

It was in 1985 that Michael E. Porter and V. Millar published an article on 'How Information Gives you Competitive Advantage' in the Harvard Business Review [25] and that the concepts of database marketing (DBM) and sales force automation (SFA) we introduced. These concepts have laid the foundation for marketing on the basis of knowledge of the needs and behaviour of the individual customer. These advanced systems require real time data integration which initially was achieved using proprietary application programming interfaces (APIs). From a technical viewpoint, CRM systems can be considered as an advancement of the earlier sales force automation (SFA) systems. SFA systems primarily support the sales process of companies whereas CRM systems integrate support for marketing, sales and service processes $[17$, p. 56].

Currently businesses are moving towards one standard-based integration powered by integration broker suites (IBS), package application integration engines or portal technologies. The choice of integration technology depends largely on the level of technical sophistication within the company and the established technology base. Often integration technologies are selected in the context of particular projects, for example a CRM implementation. In the past, this has often resulted in a variety of integration tools being deployed. Only recently have organizations started comprehending the resulting costs and moved towards a uniform middleware layer [30, pp. 2-4]. 


\section{Strategy and processes for customer management}

'Strategy is the total pattern of decisions and actions that position the organization in its environment and that are intended to achieve its long-term goals' [28, p. 85]. 'Strategy today requires a broader and more nuanced definition of competitive advantage, one that encompasses traditional sustainable advantage but that also includes more transient leverageable advantages. A leverageable advantage can be defined as a privileged market position that, however fleeting, provides a stepping stone to another privileged position. Unlike a sustainable advantage, a leverageable advantage is a way station, not a destination. But like a sustainable advantage, a leverageable advantage is a manifestation of deep and disciplined strategic thinking. It's more than just a reaction to current events; it's a deliberate move that builds on the past and prepares for the future' [3, p. 96].

Successful companies will have to establish leverageable advantages with the help of CRM technology and protect their new distinctive position by treating it only as a stepping stone to move on to the next level. 'The goal is a strategy that is forever morphing, forever conforming itself to emerging opportunities and incipient trends. The goal is an organization that is constantly making its future rather than defending its past' [9].

CRM is a strategic activity-oriented approach. It first apprehends the relationship between the enterprise and the customer and subsequently supports its re-design using a method-based approach. A CRM strategy is the guide to turn customers into assets. It is based on an understanding of how the company's competencies can create value propositions for the customers and the market segments that offer the most value potential. These competencies then generate business outcome. It does not sit in isolation but its objectives are derived from the corporate strategy, tied into the business model and then integrated with other strategies on the operative planning level.

Consequently the CRM strategy can be depicted as an interweaving of various operational strategies (see Figure 1). The company's position in the market relative to its competitors and its objectives are described in the marketing strategy. The customer strategy defines objectives based on the customer life cycle to create greater customer value and loyalty. Area strategies (sales, service, channel, product and communication strategies) derive their objectives from the marketing and customer strategies. Interweaving them helps to understand customers in the context of the market, the market segments and the market forces. This then governs other supporting operational strategies - such as HR and IS/IT. The company's operating model summarizes the strategies and contains detailed process landscapes, diagrams and organization charts.

It has now become clear that the CRM strategy is not a separate strategy on its own. Also, it is not an entirely new concept - it still builds upon strategies and concepts which have been in place for many years. But these existing strategies were often not linked or even coordinated with each other. The new idea about a CRM strategy is the interweaving of these existing strategies. The process of interweaving strategies stands for adjusting and fine-tuning already existing marketing and customer strategies. Depending on the outcome of the business evaluation, it can also connote a repositioning of the company. This process is iterative and evolutionary, highly interactive and definitively requires upper-management and board-level involvement. Subsequently the area strategies can be designed. As a result of this step, the company's DNA is created, dictating what the CRM capabilities should deliver.

A company manages its internal processes together with the development of its human, information and organization capital to deliver a differentiating value proposition. Internal processes accomplish two vital goals:

Produce, promote and deliver a value proposition for the customers. "The value a company creates is measured by the amount that buyers are willing to pay for a product or service' [25, p. 150].

Dramatically reduce costs through process improvement to perform the value activities at a lower price tag.

They can be grouped into four clusters $[13$, p. $43 ; 22$, pp. 117-9]:

- operations management processes;

- customer management processes;

- innovation processes; and

- regulatory and social processes. 


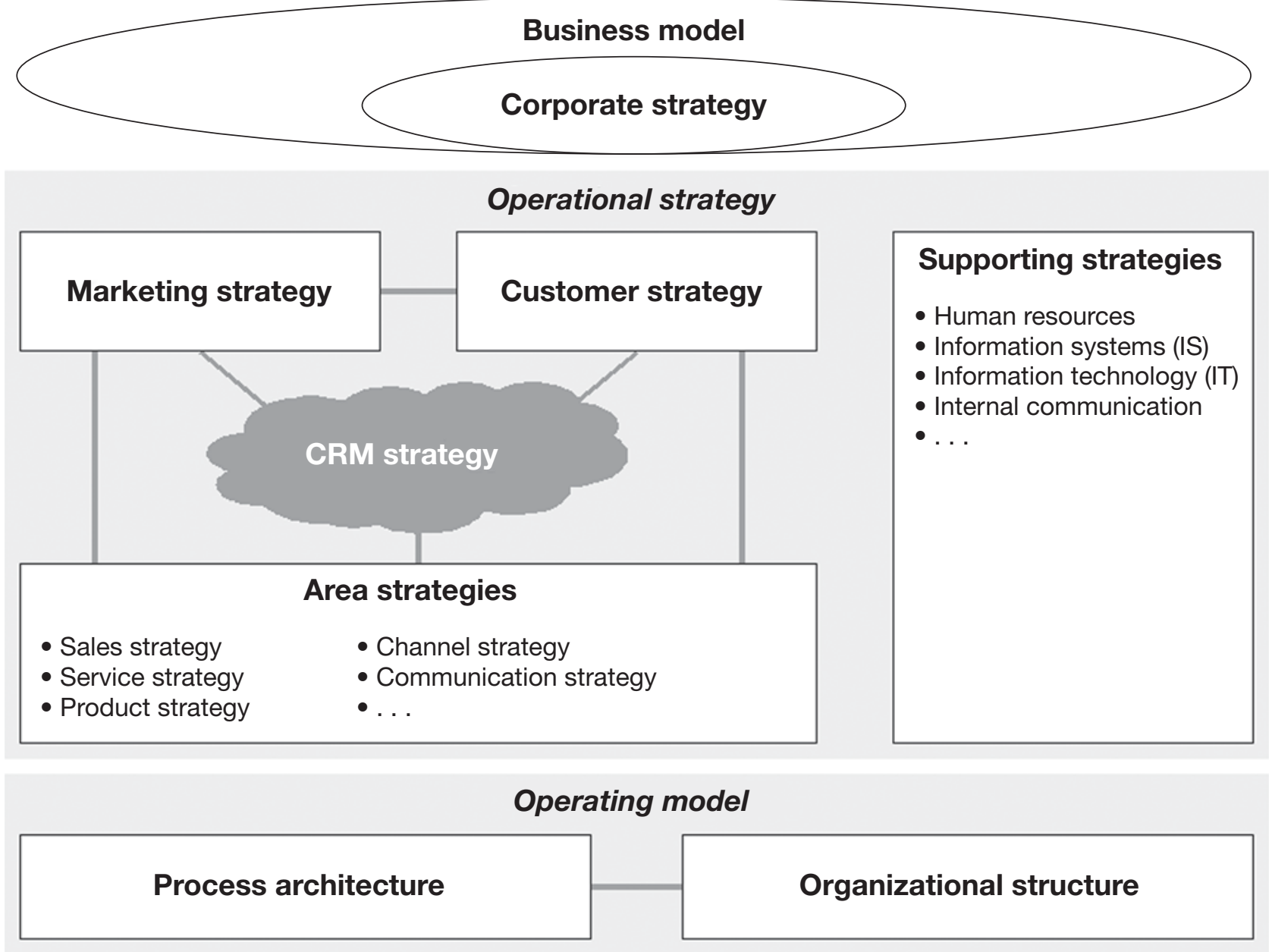

Figure 1 - The concept of CRM strategy

It is possible to tailor elements of a CRM system to a particular industry and its processes by using standardized configuration tools. Some CRM vendors pride themselves in providing pre-configured so-called vertical solutions for, for example, the automotive industry, retailing, banking or the pharmaceutical industry. As CRM systems become more and more advanced, vendors compete on their ability to propose, provide and incorporate industry best practices. Any customization specific to the company's processes is usually done by outside consultants, 'meaning that any valuable customization could be replicated by other companies' [3, p. 47]. Enterprise resource planning (ERP) systems share a similar philosophy and it was noticed in the late 1990s that extensive customization was rarely worth the effort. Most companies chose to stick with default configurations, as they noticed that modification of complex programs led to delays and cost overruns without providing a meaningful differentiation on a business level [6].

'Smart companies know that distinctive processes lie at the heart of competitive advantage' [3, p. 83]. Why do companies allow for such a trade-off then? It is because the cost savings in buying standardized solutions and the reduced risk in running them is often too tempting. Companies are '. . realizing that leveraging industry best practices far outweighs the benefit of perpetuating a unique process' [19]. It does not take long for the dominant design - the optimal way of doing business [3, p. 85] - to emerge as a best-practice process and for most companies to adopt it. But it should be realized that every company has unique circumstances that dictate the creation of quite 
different "flavours" of CRM' [26, p. 1]. Vertical solutions only go some way to meeting these demands but often miss the nuances of individual business models.

The trend toward outsourcing or even offshoring business processes will neutralize the very same processes as sources of potential competitive advantage. The processes themselves will then become part of the utility model.

\section{The current status of CRM technology}

\section{Proprietary and infrastructural technologies}

Proprietary technologies can be owned, actually or effectively, by a single company. They aid enterprises in their business strategy for competitive uniqueness, namely to distinguish themselves from other companies with a similar mission.

Infrastructural technologies, in contrast, offer far more value when shared than when used in isolation [3, pp. 17-27]. Generally they are commodities. But in early phases of its development, an infrastructural technology can take the form of a proprietary technology. As long as access to the technology is restricted, individual quick-moving and forward-looking companies often have opportunities to use it to gain advantages over rivals and differentiate themselves. These advantages are based on superior insight into the use of CRM systems and their transformational power. But the beneficial effects of new technologies diffuse throughout the entire business community through rampant copycat-ism. The window for gaining competitive edge and differentiation is open only briefly. Opportunities for achieving competitive advantage from an infrastructural technology will not be available indefinitely. When the technology's commercial potential begins to be broadly appreciated, its buildout and standardization proceeds with extreme speed. Both the technology and its modes of use become a standardized commodity. Then the advantages of foresight begin to diminish along with the advantages of easy and cheaper access. Useful new innovations tend to be rapidly incorporated into the general infrastructure as system add-ons or new releases and will be soon shared by all users. Vendors are rushing to copy one another's features: 'All distinctive uses of technology are eventually copied' [3, p. 77].
In the end of the cycle, infrastructural technologies begin to fade into the background of business and thus cease to be a concern of a company's senior decision makers. Hence the crucial variable in leveraging the strategic power of an investment into a CRM technology is the time it takes for competitors to copy this new technology and apply it as a commodity on a widespread basis. The history of IT shows that this technology replication cycle is getting shorter and shorter [3, p. 78]. This means that in the future the pay-back time available for a new technology investment is also getting slimmer. 'Today, most IT-based competitive advantages simply vanish too quickly to be meaningful' [3, p. 78].

\section{The CRM adoption cycle}

The growth of a new technology from market introduction to maturity follows a five-phased adoption cycle (see Figure 2), which is based on the Gartner Group's hype cycle diagram [5; 16, pp. 824-5].

Technology trigger A breakthrough invention, public demonstration at a congress or a product launch generates significant press and industry interest. This leads to a phase of over-enthusiasm and sometimes unrealistic projections on the business benefits of utilizing the new CRM technology as a differentiating factor. When it becomes clear that a new technology is emerging, companies invest heavily in the new infrastructure. This often requires substantial alterations to business processes. Enterprises feel that they have little choice but to invest, stay ahead or at least abreast with their competitors. But the technology is still new, it is unstable, untested and can thus cause great damage to a company's operation. 'In other words, companies are forced to install a critical new business resource before they've learned how to manage it effectively' [3, p. 109].

One current example of a technology trigger is the concept of business activity monitoring (BAM), where critical business performance indicators are monitored online to improve and fine-tune the effectiveness of business operations. BAM technology is still in its infancy and companies need to piece together applications from several vendors.

Peak of inflated expectation The new CRM technology is then pushed to its limits. There are some well-publicized stories about how companies have 


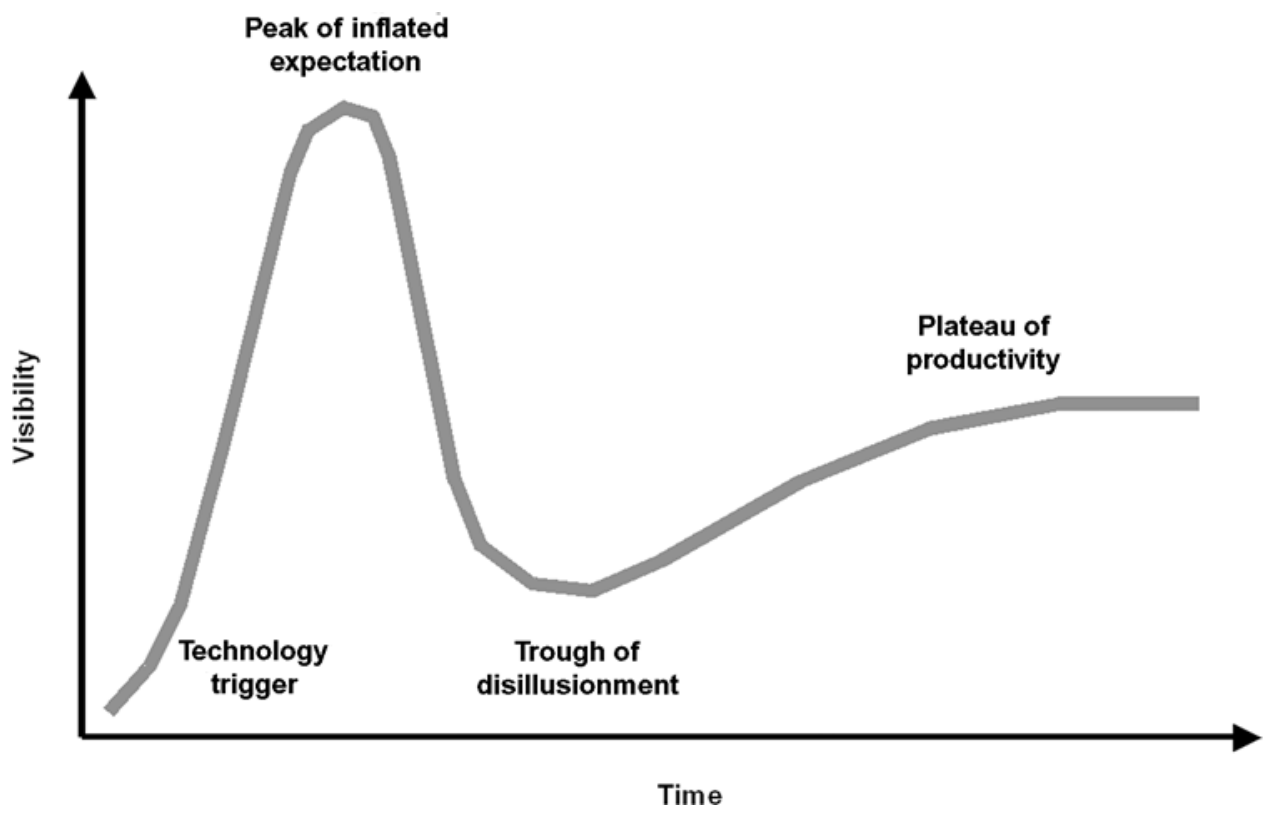

Figure 2 - CRM adoption cycle

applied it to differentiate themselves, but even more about project failures. 'The enterprises that make money during this phase are generally conference organizers, magazine publishers and consultants' [5]. Simply put, at this stage it is difficult to draw any broad conclusion about the effect of CRM systems on the competitiveness or profitability of individual businesses.

Analytical CRM, as an example of a technology at the peak, contains all techniques to analyse and optimize customer relationships. It has risen fast in visibility, vendors have just about pieced together powerful suites. But now the development is standing rather still because these suites did not find a big enough market.

Trough of disillusionment The inflated promises cannot be kept by the new technology. It rapidly becomes unfashionable and passé. Again, there is ballyhoo about the inflated and unrealistic expectations in the press.

Data mining has long been hyped as a means to discover hidden relationships in large data sets. However, the underlying algorithms are mathematically complex and only experts understand if and how well the algorithm matches the properties of the business problem. For instance, neural networks have long been examined and applied in practice, but it is still not yet fully understood when to best apply which derivative with what approach. Other application areas like selecting a target group for marketing campaigns have already matured and are widely used in practice. Because there is hardly any market for data mining workbenches, CRM vendors are now trying to hide these algorithms in their analytical CRM suites (see above). Only as analytical CRM matures will data mining also slowly climb the slope of enlightenment.

Slope of enlightenment Ongoing research and hard work is finally leading to a fine-tuning of the technology and a true understanding of its capabilities. Methodologies and tools become available to ease its introduction into companies.

An example of a technology that is only slowly being fully understood is personalization. This helps a business to fully align itself to the customer's current and specific needs and preferences. Personalization is also applied on a lower level to the company's website, to the communication centre or to product configuration. Many applications contain some simple form of personalization, such as setting user preferences; but automatically deriving information needs from just a few historical data points remains difficult. It works pretty well on customer segments when applied to marketing campaigns; on an individual level Amazon 
has pioneered a simple scheme. However, other more complex applications have been shown to be far too inaccurate.

Plateau of profitability Stringent business cases prove the real world benefits of the new technology. Methodologies and tools are becoming more and more fine-tuned and stable as they enter new generations. The connection between technology and business strategy has been established. The final visibility (or height of the curve in the adoption cycle) 'varies according to whether the technology is broadly applicable or benefits only to niche markets' [5].

A good example of a mature CRM technology is static reporting. It has been around since the days of mainframes and gives users push-based information on anything and everything that is happening in the core business systems of the enterprise. Similarly, online analytical processing (OLAP) is a technique which is in fact older than the concept of the relational database and has now left its niche market and become a widely used commodity.

\section{The quandary of overshooting}

Overshooting is the process by which the performance of a technology product comes to exceed the requirements of most of its users. Looking at the adoption cycle, it mostly happens in the phase between 'technology trigger' and 'peak of inflated expectation' or much later after it has reached the 'plateau of productivity'. 'The pace of technological progress in products frequently exceeds the rate of performance improvement that mainstream customers demand or can absorb. As a consequence, products whose features and functionality closely match market needs today often follow a trajectory of improvement by which they overshoot mainstream market needs tomorrow. And products that seriously underperform today, relative to customer expectations in mainstream markets, may become directly performance-competitive tomorrow' [2, p. xxii]. Companies tend to achieve the greatest gains in the earliest stages of a new technology, after which the practical benefits of further technological advances decline abruptly [7, p. 62].

Overshooting is a common phenomenon with CRM vendors. Spurred by the need to satisfy their most demanding customers and to protect their highestmargin sales with their best customers, CRM vendors compete fiercely to advance the state of the art, adding new features and functions to their CRM products in order to stay on the coveted cutting edge. But each new version of a CRM system overshoots the needs of some customers, and makes the product too complex for them. So these businesses often respond by starting a system evaluation, frequently followed by switching to leaner CRM systems from other suppliers. Some CRM vendors are slow to accept the reality of overshooting. They want to believe that the needs of businesses will march in lockstep forever. But Moore's Law is not governing buyers! Businesses simply do not need that extra bit of CRM feature; they are satisfied with what they have already. The CRM commodity products are good enough.

The tendency to overshoot opens the door for cheaper alternatives. That explains the increasing popularity of open-source software. The leading Web server software is now the open-source Apache with a 65 per cent market share [24]. The Linux operating system steals market share from Windows and proprietary Unix-based systems. Free office productivity suites like OpenOffice are competing with established products from Microsoft Office. There is little reason to doubt that the same trend is going to happen to CRM applications.

\section{CRM as a utility model}

Ultimately CRM systems as software may just disappear. At least this is what Salesforce.com pioneered and is promising its customers. Salesforce.com and other vendors like Siebel are offering 'on-demand' products where access to CRM applications is provided over the Internet for a monthly fee. Companies buy their information technologies as services provided over the Internet rather than owning and maintaining all their own hardware and software [8, p. 105]. 'This may herald the final step in business software's brisk march toward commoditization: from in-house programs to contractor-written applications to packaged applications to fee-based services' [3, p. $55-$ with respect to the transportation industry]. However, it remains to be seen how fully the utility model will actually be received and implemented by companies. There are enormous technical challenges, from establishing complex but robust data standards [14] to setting up huge, reliable and secure data centres. Many executives remain sceptical, since they wasted time and money on Internet initiatives in the late 1990s during the e-commerce hype. 


\section{Recommendations}

The real challenge is to sustain competitive advantage through a differentiating use of CRM technology long enough to earn a solid return on investment and to leverage the technological advantage into more durable advantages - increased customer base and retention, process efficiency or a better-known brand. The time has come for a more conservative approach to CRM technology investment. As CRM strategy, processes and systems mature, successful companies will not be those that pursue every innovation, but rather those that invest carefully and perform pragmatic planning.

\section{Spend less and late}

Non-discretionary IT costs, which appear to be fixed over the long-term, can actually be trimmed down.
Expenditure on day-to-day operations and maintenance of existing applications can be reduced by consolidation, using shared service infrastructure, outsourcing or offshoring. Cost reduction has to be achieved without a subsequent loss of efficiency. These efficiency gains will subsequently be re-invested to strengthen IT capabilities and core business, ultimately leading to a leverageable advantage.

The IT Management Framework (Figure 3) allows the comprehensive reshaping of processes to achieve significant improvements in effectiveness and efficiency. It helps to avoid IT architectures looking like 'a plate of cooked spaghetti' [20, p. 63] with many systems patched in and interconnected with each other.

Companies that stay off the leading edge CRM technology reduce their chance of having bug-infested or soon-to-be-replaced technology. They can learn from others and avoid the mistakes and high costs of experimentation experienced by early movers. In the

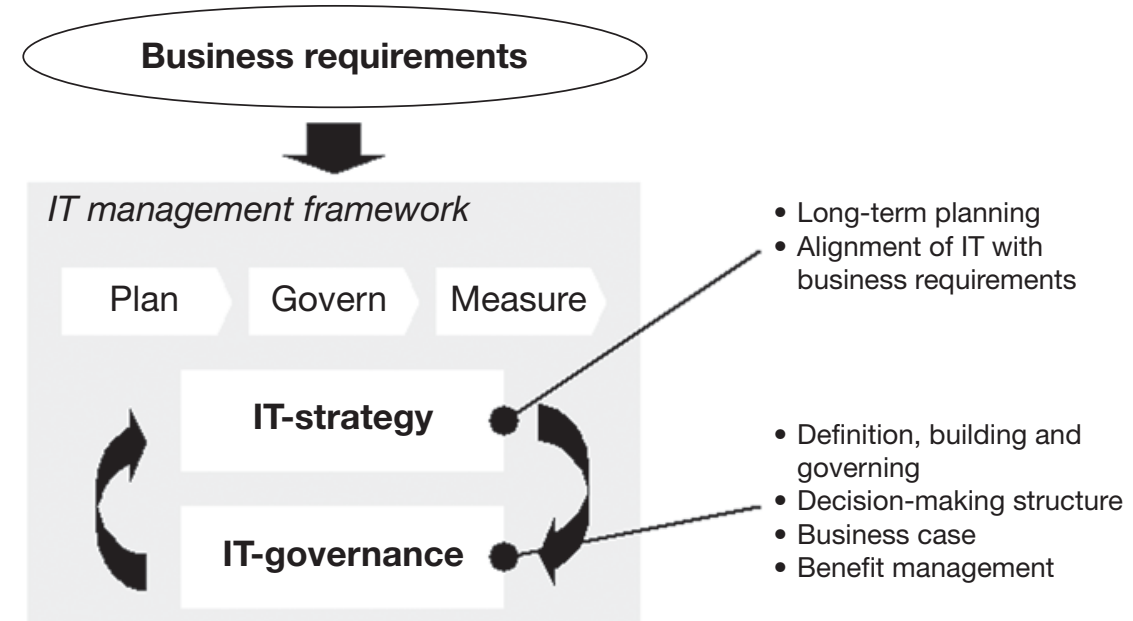

Building blocks

\begin{tabular}{|l|}
\hline \multicolumn{1}{|c|}{ Application } \\
development
\end{tabular}

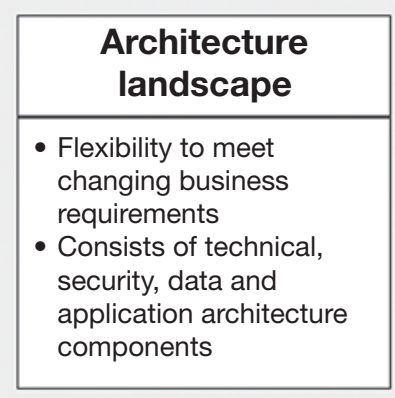

Management of resources

- Maximize value of IT investments

- Career development

- Knowledge management

- Supplier management

- Quality assurance 
end, they might even be able to build better CRM systems.

It is also vital to consider the positive effects of joint efforts. Groups of companies may want to work together to establish a basic building platform for reaching further positions of leverageable advantage.

\section{Plan big and high-level}

IT architecture is forming a bridge between business and technology by integrating technology solutions with business goals [1, p. 2]. Hence it can only be driven from business strategy. 'IT is never more important than the business functions it supports' [10, p. 1].

A five-step approach can be applied to develop a high-level model [12, p. 3 - extended]:

- Identify up to eight macro business processes that encapsulate everything the company does. The targeted process customers (general marketspace, prospects, customers, external partners or other processes) are ideal criteria for separating these processes [22, p. 229; 27, p. 25].

- Link these macro processes back to the business strategy by using business drivers and critical success factors.

- Model these macro processes.

- Indicate organizational responsibility. 'Organizational issues are important because the success of a CRM system depends on its users, many of whom have direct contact with customers' [4, p. 53].

- Identify categories of data involved in the macro business processes [21; 22, pp. 109-15]. Build an Information Architecture (IA) which acts as 'a coherent set of strategies and plans for information access and delivery inside' [11, p. 17] the organization. Then measure information capital readiness as a degree of the preparedness of the company to support the business strategy with its existing information architecture [13, pp. 264-7].

Following these recommendations, companies will ensure that they are not investing in technology but in business innovation [10, p. 4] and thus ensure that they can indeed turn a commodity into a differentiating factor.

\section{References}

[1] Kearney, A.T. and Harris Interactive (2003) 'The Road to Business Value: An Integrated Approach to IT Investment'. Chicago: Study by Kearney \& Harris.

[2] Christensen, C. (1997) The Innovator's Dilemma: When New Technologies Cause Great Firms To Fail. Boston: Harvard Business School Press.

[3] Carr, N. (2004) Does IT Matter? Boston: Harvard Business School Press.

[4] Ebner, M., A. Hu, D. Levitt, J. McCrory (2002) 'How to Rescue CRM', McKinsey Quarterly, Special Edition: Technology.

[5] Gartner Group (2003) Building Business Benefits from CRM: How To Design Strategy, People, Processes And Architecture To Succeed. Gartner Group Executive Report Series, R 274-1742.

[6] Gill, P. (1999) 'ERP: Keep it Simple', Information Week 9 August. Available at: www.informationweek.com/747/ 47aderp.htm (accessed 27 December 2004).

[7] Gordon, R. (2000) 'Does the New Economy Measure Up to the Great Inventions of the Past?', Journal of Economic Perspectives 4(14).

[8] Hagel III, J. and J. Brown (2001) 'Your Next IT Strategy', Harvard Business Review October.

[9] Hamel, G. and L. Välikangas (2003) 'The Quest for Resilience', Harvard Business Review September.

[10] Harris, J. and J. Brooks (2003). Why IT Still Matters. Accenture Institute for Strategic Change, Research Note.

[11] Hourican R. (2002) 'Information Architectures: What Are They?' Business Information Review 19(3).

[12] James, G. (2003) High-Level Architecture Models Give Enterprise Perspective. Gartner Group Research Note TU-21-1018.

[13] Kaplan, R. and D. Norton (2004) Strategy Maps: Converting Intangible Assets into Tangible Outcomes. Boston MA: Harvard Business School Press.

[14] Koch, C. (2003) 'The Battle for Web Services', CIO, 1 October. Available at: www.cio.com/archive/100103/standards.html (accessed 27 December 2004).

[15] Kotler, P., G. Armstrong, J. Saunders and V. Wong (1996) Principles of Marketing. London: Prentice Hall Europe.

[16] Landry, S. and J. Koch (2003) 'Der Hype Cycle neuer Technologien für Finanzdienstleistungen', Die Bank 12.

[17] Link J., N. Gerth and E. Voßbeck (2000) MarketingControlling. Munich: Verlag Vahlen.

[18] Link, J. and V. Hildebrand (1993) Database Marketing und Computer Aided Selling. Munich: Verlag Vahlen. 
[19] Lynch, K. (2004) 'Network Software: Finding the Perfect Fit', Inbound Logistics November. Available at: www.inboundlogistics.com/articles/itmatters/itmatters 1102.shtml (accessed 28 December 2004).

[20] Mattern, F., S. Schönwälder and W. Stein (2003) 'Fighting Complexity in IT', McKinsey Quarterly 1.

[21] Messner, W. (2004) 'The Beauty and Importance of Quality Customer Information', The Marketing Review 4(3): 279-290.

[22] Messner, W. (2005) CRM bei Banken: Ein Vorgehensmodell zur Erarbeitung einer Strategie, Prozess- und Systemarchitektur. Norderstedt: BoD Verlag.

[23] Messner, W. (2005) 'Offshoring IT to India as an Enabler for Banking Business Transformation', in P. Brudenall (ed.) Technology and Offshore Outsourcing Strategies. London: Palgrave MacMillan.

[24] Netcraft: (2003) 'July 2003 Web Server Survey'. Available at: http://news.netcraft.com/archives/2003/07/ 02/july_2003_web_server_survey.html (accessed 27 December 2004).
[25] Porter, M. and V. Millar (1985) 'How Information Gives you Competitive Advantage', Harvard Business Review July-August.

[26] Radcliffe, J. (2003) Five Factors Shape Every Enterprise's CRM Strategy. Gartner Group Research Note DF21-3450, 3 December.

[27] Schmid, R., V. Bach and H. Österle (2000) 'Mit Customer Relationship Management zum Prozessportal', in V. Bach and H. Österle (eds) Customer Relationship Management in der Praxis: Erfolgreiche Wege zu kundenzentrierten Lösungen. Berlin: Springer Verlag.

[28] Slack, N., S. Chambers and R. Johnston (2001) Operations Management, $3^{\text {rd }}$ edn. London: Financial Times and Prentice Hall.

[29] Slywotzky, A. and R. Wise (2003) 'An Unfinished Revolution', MIT Sloan Management Review 44(3).

[30] Wood, B. (2002) Customer Relationship Management Integration Trends. Gartner Group Research Note COM17-7374, September. 